\title{
Geochemical Characteristics and Oil Source Correlation of Minfeng Area, Dongying Depression, China
}

\author{
Dongmei Bo, ${ }^{1}$ Lin Jiang $\mathbb{D}^{1},{ }^{1}$ Wen Zhao $\mathbb{D}^{1,2}$ Youlu Jiang, ${ }^{3}$ Hua Liu, ${ }^{3}$ and Haowen Ou ${ }^{4}$ \\ ${ }^{1}$ Research Institute of Petroleum Exploration and Development, PetroChina, Beijing 100083, China \\ ${ }^{2}$ College of Geosciences, China University of Petroleum (Beijing), Beijing 102249, China \\ ${ }^{3}$ College of Geosciences, China University of Petroleum (East China), Qingdao 266580, China \\ ${ }^{4}$ Dongxin Geological Department, Shengli Oilfield Company, Sinopec, Dongying 100083, China \\ Correspondence should be addressed to Lin Jiang; jianglin01@petrochina.com.cn and Wen Zhao; zhaow625@126.com
}

Received 26 March 2021; Revised 13 May 2021; Accepted 19 May 2021; Published 1 June 2021

Academic Editor: Chenhao Sun

Copyright (c) 2021 Dongmei Bo et al. This is an open access article distributed under the Creative Commons Attribution License, which permits unrestricted use, distribution, and reproduction in any medium, provided the original work is properly cited.

\begin{abstract}
The identification of the oil-source correlation plays a significant role in petroleum exploration and development. In this study, we identify the oil-source correlation by a hierarchical cluster analysis method combined with traditional methods. The results shed light on the oil-source correlation in Minfeng area and revealed the oil migration and accumulation process. The crude oil in different structural belts and different horizons has different geochemical characteristics. According to the four types of crude oil and their planner distribution, it was considered that the crude oil mainly migrates along with favorable sand bodies and unconformity surfaces in the lateral direction and then charged and accumulated in the glutenite of Sha3 and Sha4 members since the area from sag to Yan Jia Oil and the gas field was lacking of oil source faults. Further analysis shows that the traps of fault blocks in Yong'anzhen are formed in the same phase, while the crude oil generated in the early stage is charged and accumulated in the fault block of the near source. Along with increasing of the buried depth of source rocks, the overlying source rocks gradually entered into the hydrocarbon generation phase, when crude oil started to charge in the fault blocks farther away.
\end{abstract}

\section{Introduction}

Identifying the source of discovered oil (also called oil-source correlation) is of vital significance for oil petroleum exploration and development [1]. Therefore, the oil-source correlation is conducted at each confidence level for reservoir exploration and development in all sedimentary basins [2, 3]. Along with the continuous discoveries of oil and gas in the Minfeng area in recent years, the oil-source relationship has attracted researchers' attention gradually.

Although the physical and chemical properties of hydrocarbon from the same set of source rocks change slightly in the process of hydrocarbon migration, they still show certain regularity [4]. Therefore, the establishment of the connection between source rocks and reservoir can effectively guide the exploration and development of oil and gas. Oil source corre- lation is to clarify the migration path of oil and gas by studying this law [5]. At present, oil source correlation is mainly studied by carbon isotope characteristics and biomarkers.

When using carbon isotopes to make oil source correlation, the carbon isotopic values of kerogen or extractable organic matter are mainly compared with those of hydrocarbon [6]. If the difference between the two results is small, it indicates that they are correlated. Since biomarkers are basically not affected by hydrocarbon secondary processes, they can provide more information about the origin of source rocks, sedimentary environment, and thermal maturity and play an important role in oil-source correlation. The nalkane components can reflect the type of organic matter, the nature of sedimentary environment, and the degree of thermal evolution. Previous studies on saturated hydrocarbon chromatogram showed that different peak values of 
carbon number could be used to determine the origin of hydrocarbon. The low-carbon number group was mainly the combination of low aquatic organisms, while the later peak high-carbon number group was mainly the product of the biochemical interaction between aquatic and terrestrial plants. In isoprenoids, the $\mathrm{Pr} / \mathrm{Ph}$ ratio is usually used to characterize the sedimentary environment. Generally, when $\mathrm{Pr} / \mathrm{Ph}$ is greater than 3, it indicates the oxidation environment and organic matter comes from terrestrial higher plants. When $\mathrm{Pr} / \mathrm{Ph}$ is less than 0.8 , it indicates the reduction environment and the $\mathrm{Pr} / \mathrm{Ph}$ ratio of marine crude oil is usually small. Steranes are mainly derived from phytosterols in plankton, among which the distribution of $\mathrm{C}_{27}-\mathrm{C}_{28}-\mathrm{C}_{29}$ sterol homologs can be used to indicate different sedimentary environments and are widely used in oil-source correlation.

There are many methods during the treatment process of geochemical data in oil-source correlation, such as the direct inspection of chromatograms [7], the homologous series distribution pattern [8], 2D/3D ternary plots, or cross-plots of biomarkers ratio [9]. The above standard methods are widely adopted in the oil-source correlation process. However, these methods also have disadvantages. Although the characters of large numbers of samples can be described with the cross/ternary plot method, it has limitations when working with multiple parameters [10]. Multiple biomarkers can be well considered with the methods of chromatograms or homologous series distribution patterns. Since only a few samples can be tested, the geochemical characteristics of the oil system cannot be well considered, which will improve the uncertainties in oil-source correlation and cannot meet the accuracy needed in oil-source correlation $[11,12]$. To overcome the above limitations, researchers adopt multivariate statistical analysis methods in the oil-source correlation, which can process multiple geochemical parameters and large numbers of samples simultaneously $[13,14]$. Multivariate statistical methods have become the focus in the oil-source correlation process $[15,16]$. As a typical multivariate statistical method, hierarchical cluster analysis (HCA) (also called hierarchical cluster) is considered to be a helpful method in oil-source correlation $[17,18]$. It is an algorithm that groups similar objects into groups called clusters. The endpoint is a set of clusters, where each cluster is distinct from the other cluster and the items within each cluster are broadly similar to each other. In this work, to investigate the oil-source correlation directly and comprehensively, HCA combined with standard treatment methods (fingerprinting comparison, sterane and terpane fingerprint comparison, and scatter diagram method) are adopted.

The rest of this paper is organized as follows. In Section 2, the geological background of the Minfeng area will be introduced. The geochemical characteristics of crude oil from 25 samples are tested; four crude oil types are divided in Section 3. In Section 4, we use common treatments combined with HAC to investigate the oil-source correlation. The oilsource relationship is well correlated through the systematic collection and analysis of crude oil and oil sand samples, and the hydrocarbon migration and accumulation process are revealed in the Minfeng area.

\section{Geological Background}

Minfeng area is located in the northeast of the central uplift of Dongying Depression in the Bohai Bay Basin, China, with about $460 \mathrm{~km}^{2}$. It is bordering on Chenjiazhuang uplift to the north, central uplift belt to the south, Qingtouzi uplift to the east, and Shengtuo Oilfield to the west (Figure 1). During the deep rift period, under the control of paleoclimate and water body variation, three sets of effective source rock measures with different lithological combinations and stratigraphic development features are formed in Mingfeng subsag (upper Sha4 submember, lower Sha3 submember, and middle Sha3 submember) [19]. The primary production zone of the Yonganzhen oil and gas field is the glutenite reservoirs of Paleogene Sha2 member (Es2) and upper Sha4 submemer (Es4s), while the significant production zone of the Yanjia oil and gas field is the glutenite reservoir of Sha3 member (Es3) and Sha4 member (Es4).

\section{Geochemical Characteristics}

The crude oil's biomarker characteristics in different oil and gas fields in the study area are different. According to the gas chromatographic characteristics and steroid terpane characteristics of the saturated hydrocarbon in the samples, the crude oil of the study area could be divided into four types (as shown in Table 1.).

(1) Type A is featured by smooth distribution curves of $\mathrm{n}$-alkanes when the bimodal OEP value is generally less than 1.1, which means that there is no distinct odd-even predominance; the $\sum \mathrm{C}_{21}{ }^{-} / \sum \mathrm{C}_{22}{ }^{+}$value is more significant than $0.7, \mathrm{C}_{21}+\mathrm{C}_{22} /\left(\mathrm{C}_{28}+\mathrm{C}_{29}\right)$ is greater than 1.3, and the $\mathrm{Pr} / \mathrm{Ph}$ ratio is larger than 0.5 ; the gammacerane index is greater than 0.2 ; the $\mathrm{C}_{27}$ sterane content is low, $\alpha \alpha \alpha \mathrm{RC}_{27} /\left(\mathrm{C}_{27}+\mathrm{C}_{28}+\right.$ $\mathrm{C}_{29}$ ) is generally less than 0.3 , and $\alpha \beta \beta \mathrm{S} / \alpha \alpha \alpha \mathrm{R}$ is usually less than 0.3 , while $\alpha \alpha \alpha 20 \mathrm{~S} /(20 \mathrm{R}+20 \mathrm{~S})$ of $\mathrm{C}_{29}$ sterane is greater than 0.4 , indicating a high thermal evolution degree. The typical crude oil of type $\mathrm{A}$ is that in upper Sha4 submember of Well Yong 921X19 in the Yanjia oil and gas field, which mainly distributes in the glutenite interval of Sha3 and Sha4 members in the Yanjia oil and gas field as well as the sandstone interval of Sha2 member in Yong3 Block of the Yonganzhen oil and gas field

(2) Type B shows an obvious bimodal postpeak in the nalkane distribution curve, where odd number carbon is taken predominance and CPI is greater than 1.1; the $\sum \mathrm{C}_{21}{ }^{-} / \sum \mathrm{C}_{22}{ }^{+}$value is about 0.5 , the $\mathrm{C}_{21}+\mathrm{C}_{22} /($ $\mathrm{C}_{28}+\mathrm{C}_{29}$ ) value is about 0.9 , and the $\mathrm{Pr} / \mathrm{Ph}$ ratio is generally less than 0.5 ; the gammacerane content is high and the gammacerane index is greater than 0.2 , the $\mathrm{Ts} /(\mathrm{Ts}+\mathrm{Tm})$ value is less than $0.4 ; \alpha \alpha \alpha \mathrm{R}$ $\mathrm{C}_{27} /\left(\mathrm{C}_{27}+\mathrm{C}_{28}+\mathrm{C}_{29}\right)$ had a value of 0.3-0.4, $\mathrm{C}_{29} \alpha \alpha$ $\alpha 20 \mathrm{~S} /(20 \mathrm{R}+20 \mathrm{~S})$ has a value of $0.37-0.48$, and $\alpha \beta \beta$ $\mathrm{SC}_{27} / \alpha \alpha \alpha \mathrm{RC}_{27}$ had a value of 0.3 to 0.5. Type B's typical crude oil is that of Sha 2 member of well Ce77 in 


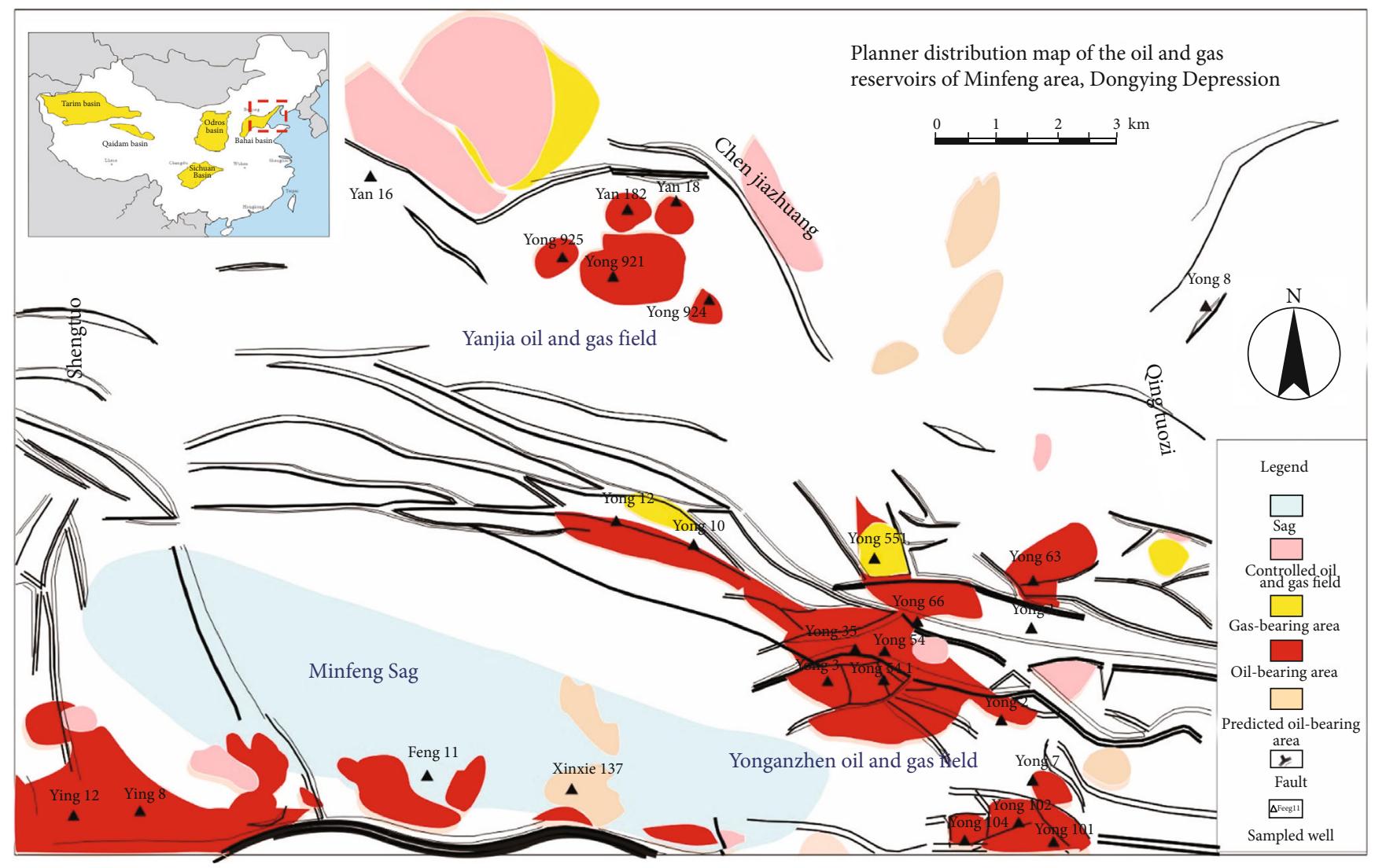

Figure 1: Map of the main sedimentary basins of China and hydrocarbon distribution in Minfeng area, Dongying Depression. On the upper map, the yellow is the sedimentary basin. In the lower map, the grey is the subsag; red represents the oil-bearing area and yellow represents the gas-bearing area.

TABLE 1: Crude oil geochemical characteristics of four types.

\begin{tabular}{|c|c|c|c|c|}
\hline Type & $\mathrm{A}$ & B & $\mathrm{C}$ & $\mathrm{D}$ \\
\hline OEP & $<1.1$ & $>1.1$ & $<1.1$ & $>1.1$ \\
\hline$\sum \mathrm{C}_{21}{ }^{-} / \sum \mathrm{C}_{22}{ }^{+}$ & $>0.7$ & 0.5 & $>1.3$ & 0.5 \\
\hline $\mathrm{C}_{21}+\mathrm{C}_{22} /\left(\mathrm{C}_{28}+\mathrm{C}_{29}\right)$ & $>1.3$ & 0.9 & $>1.3$ & 0.9 \\
\hline $\mathrm{Pr} / \mathrm{Ph}$ & $>0.5$ & $<0.5$ & $<0.5$ & $<0.5$ \\
\hline Gammacerane index & $>0.2$ & $>0.2$ & $>0.3$ & $0.1-0.3$ \\
\hline$\alpha \alpha \alpha \mathrm{RC}_{27} /\left(\mathrm{C}_{27}+\mathrm{C}_{28}+\mathrm{C}_{29}\right)$ & $<0.3$ & $0.3-0.4$ & $>0.38$ & $0.3-0.4$ \\
\hline$\alpha \alpha \alpha 20 \mathrm{~S} /(20 \mathrm{R}+20 \mathrm{~S})$ of $\mathrm{C}_{29}$ & $>0.4$ & $0.37-0.48$ & $<0.35$ & $0.38-0.5$ \\
\hline $\mathrm{Ts} /(\mathrm{Ts}+\mathrm{Tm})$ & $<0.35$ & $<0.4$ & $<0.35$ & $0.26-0.4$ \\
\hline$\alpha \beta \beta \mathrm{SC}_{27} / \alpha \alpha \alpha \mathrm{R} \mathrm{C}_{27}$ & $<0.3$ & $0.3-0.5$ & $<0.3$ & $0.4-0.5$ \\
\hline$C_{29} \beta \beta /(\beta \beta+\alpha \alpha)$ & $<0.32$ & $0.35-0.42$ & $<0.32$ & $0.35-0.42$ \\
\hline
\end{tabular}

Yong3 Blocks, which mainly distributes in the Yong2, Yong3, Yong12, and Yong66 Blocks in Yonganzhen area

(3) Type $\mathrm{C}$ is characterized by the typical bimodal prepeak type of the n-alkane distribution curve with the carbon number of $\mathrm{C}_{17}$ in the main peak, OEP and CPI values are generally less than 1.1, the C21 $+\mathrm{C} 22 /\left(\mathrm{C}_{28}+\mathrm{C}_{29}\right)$ value is generally greater than
1.3, $\sum \mathrm{C}_{21}{ }^{-} / \sum \mathrm{C}_{22}{ }^{+}$is greater than 1.3 , and the $\mathrm{Pr} / \mathrm{Ph}$ ratio is less than 0.5 . The gammacerane content is high and the gammacerane index is greater than 0.3 , the Ts/(Ts $+\mathrm{Tm})$ value is less than 0.35; the $\alpha \alpha$ $\alpha \mathrm{RC}_{27} /\left(\mathrm{C}_{27}+\mathrm{C}_{28}+\mathrm{C}_{29}\right)$ value is greater than 0.38 , the $\mathrm{C}_{29} \alpha \alpha \alpha 20 \mathrm{~S} /(20 \mathrm{R}+20 \mathrm{~S})$ value is less than 0.35 , the $\mathrm{C}_{29} \beta \beta /(\beta \beta+\alpha \alpha)$ value is less than 0.32 , and the $\alpha \beta \beta \mathrm{S} / \alpha \alpha \alpha \mathrm{RC}_{27}$ value is less than 0.3. The typical crude oil of type $\mathrm{C}$ is mainly produced from Sha3 member of Yong63-13 Block, which distributes in the reservoirs of middle Sha3 submember in Yong63 Block and Yong2 Block of the Yonganzhen oil field and Minfeng subsag

(4) Type D shows a single peak in the n-alkane distribution curve. The OEP is greater than 1.1 , the $\sum \mathrm{C}_{21}{ }^{-}$/ $\sum \mathrm{C}_{22}{ }^{+}$value is around 0.5 , and the $\mathrm{Pr} / \mathrm{Ph}$ ratio is generally less than 0.5 . The gammacerane content is high and the gammacerane index is between 0.1 and 0.3 ; $\mathrm{Ts} /(\mathrm{Ts}+\mathrm{Tm})$ has a value of $0.26-0.40 ; \alpha \alpha \alpha \mathrm{RC}_{27} /($ $\mathrm{C}_{27}+\mathrm{C}_{28}+\mathrm{C}_{29}$ ) has a value of 0.3 to $0.4, \mathrm{C}_{29} \alpha \alpha \alpha 20$ $\mathrm{S} /(20 \mathrm{R}+20 \mathrm{~S})$ has a value of $0.38-0.5, \mathrm{C}_{29} \beta \beta /(\beta \beta+$ $\alpha \alpha)$ has a value of 0.35 to 0.42 , and $\alpha \beta \beta \mathrm{S} \mathrm{C}_{27} / \alpha \alpha \alpha \mathrm{R}$ $\mathrm{C}_{27}$ has a value of 0.4 to 0.5 . This kind is produced from well 112 in middle Sha3 submember, which mainly distributes in the Minfeng Sag 


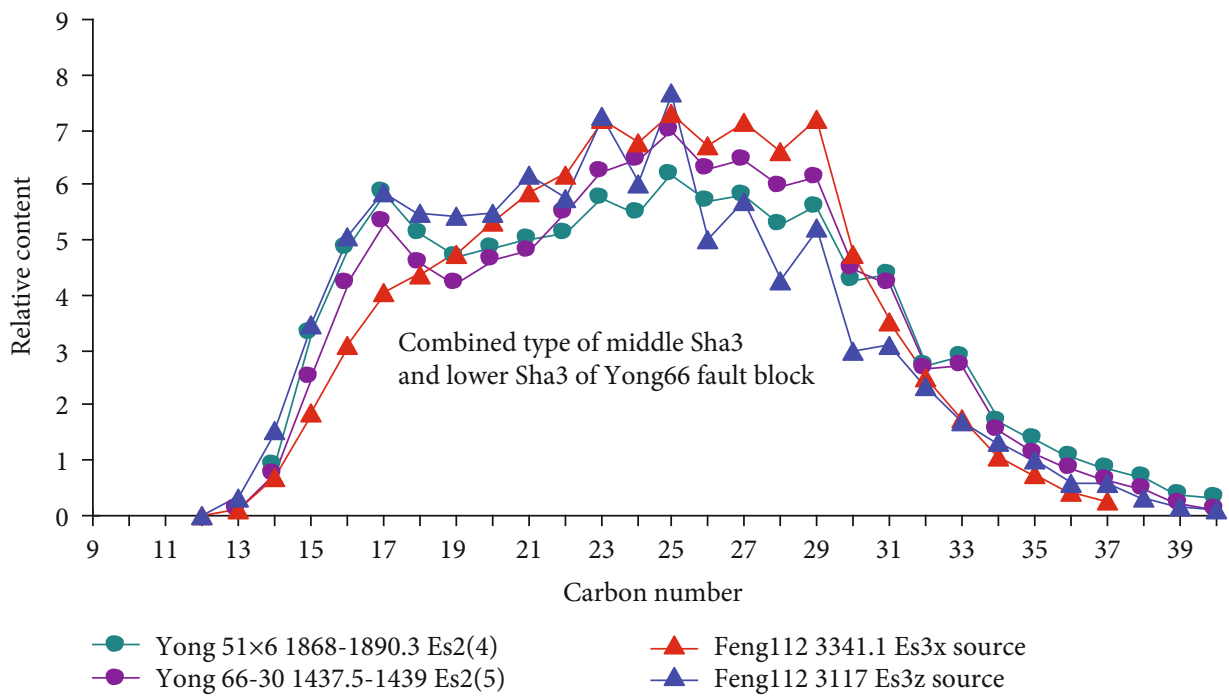

(a)

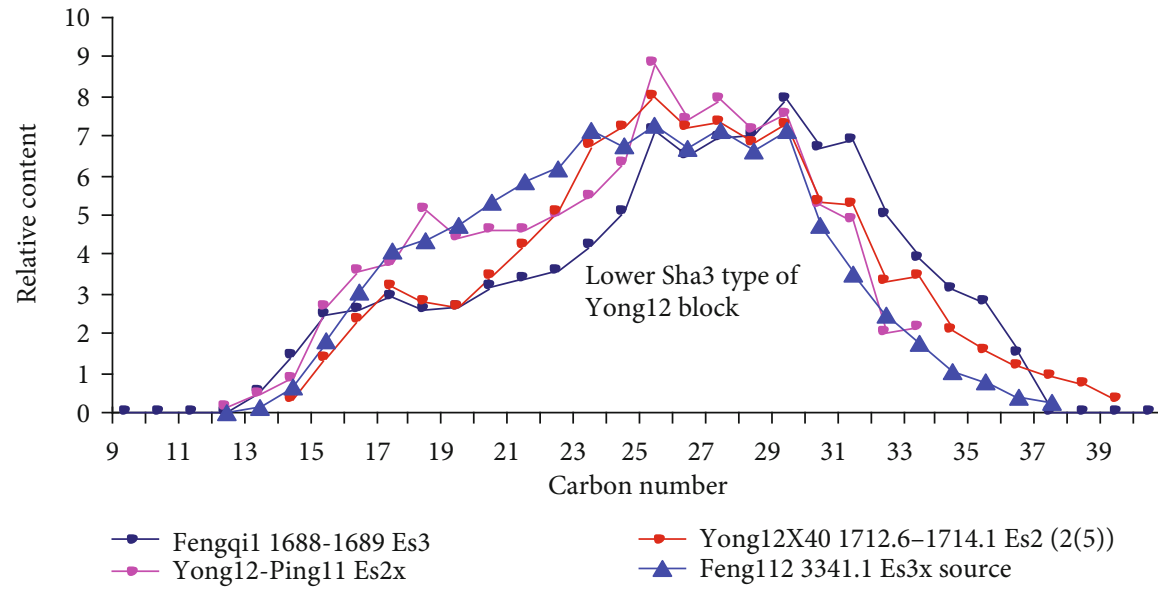

(b)

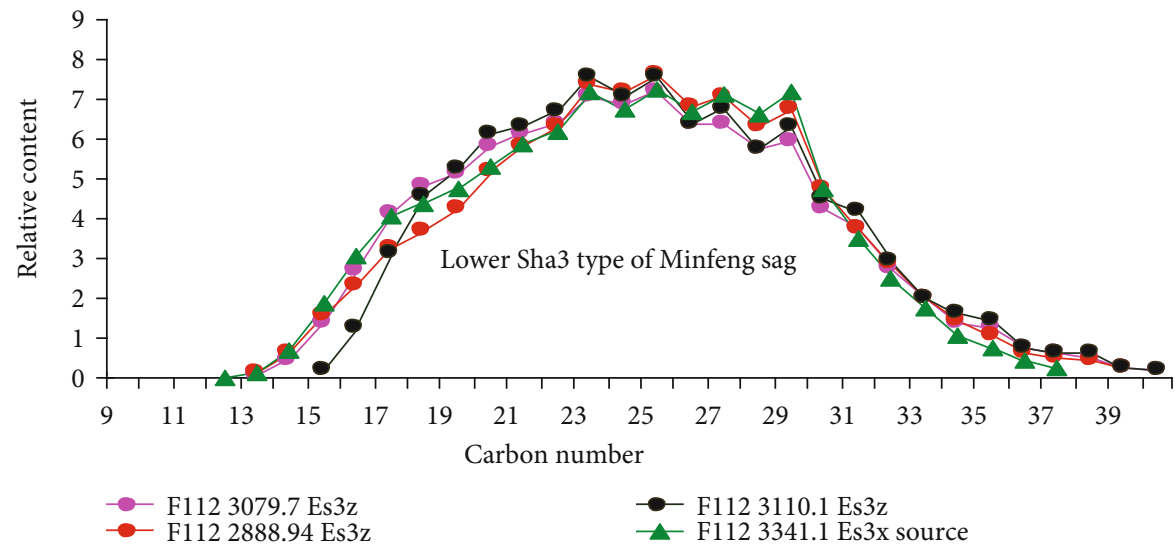

(c)

Figure 2: Continued. 


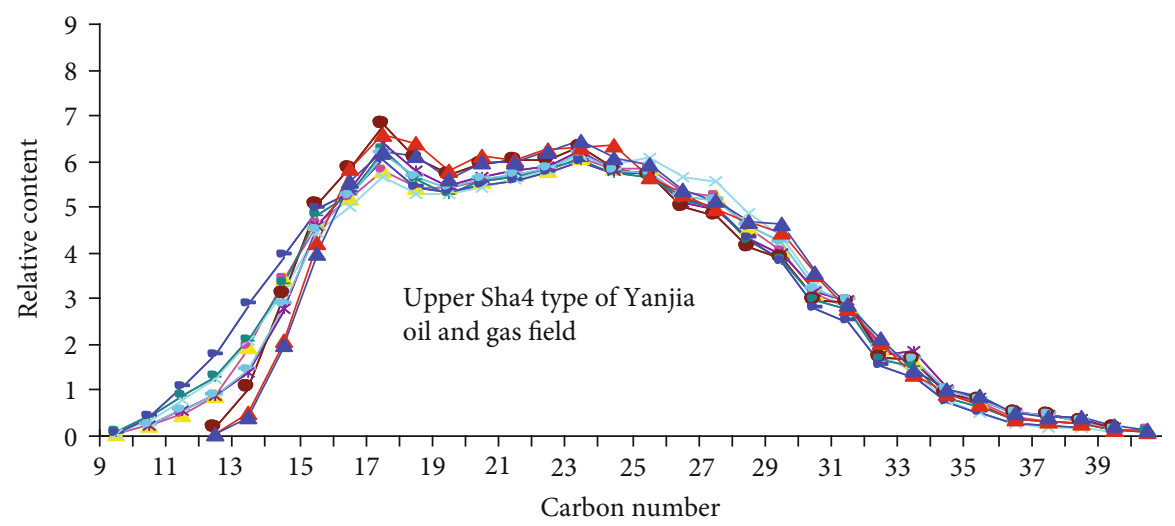

- Yan $162122-2125$ Es3x $\rightarrow$ Yan 16X9 2485.1-2496 Es3x

* Yan 18-2 2217.7-2238.2 Es3x

$\rightarrow$ Yan 182-3 2176.4-2211 Es3(2)

— Yan 182-6 2708-2724 Es4

(d)

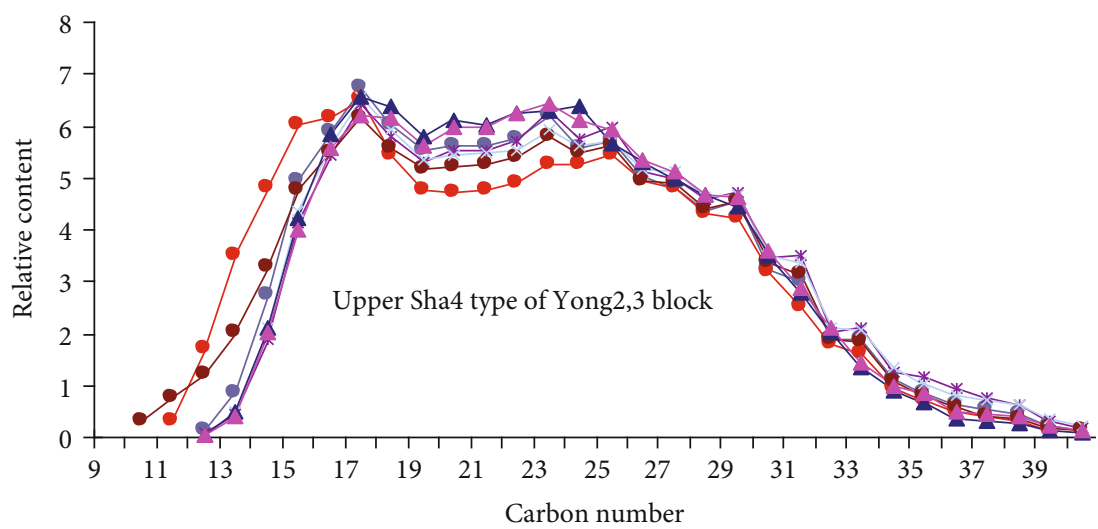

$\rightarrow-$ Yong2X17 2420.8-2422.8 Es2 (9)

- Yong3-36 1800 Es2

* Yong3C10 2178.3-2179.8 Es2 (5)

- Yong3X156 2418.5-2421.5 Es2 (10)

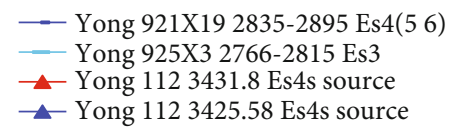

- Yong 1123431.8 Es4s source

— Yong 1123425.58 Es4s source

$\rightarrow$ Yong3C77 1983.9-1989 Es2 (3)

—— Feng112 3431.8 Es4s source

— Feng112 3425.58 Es4s source

(e)

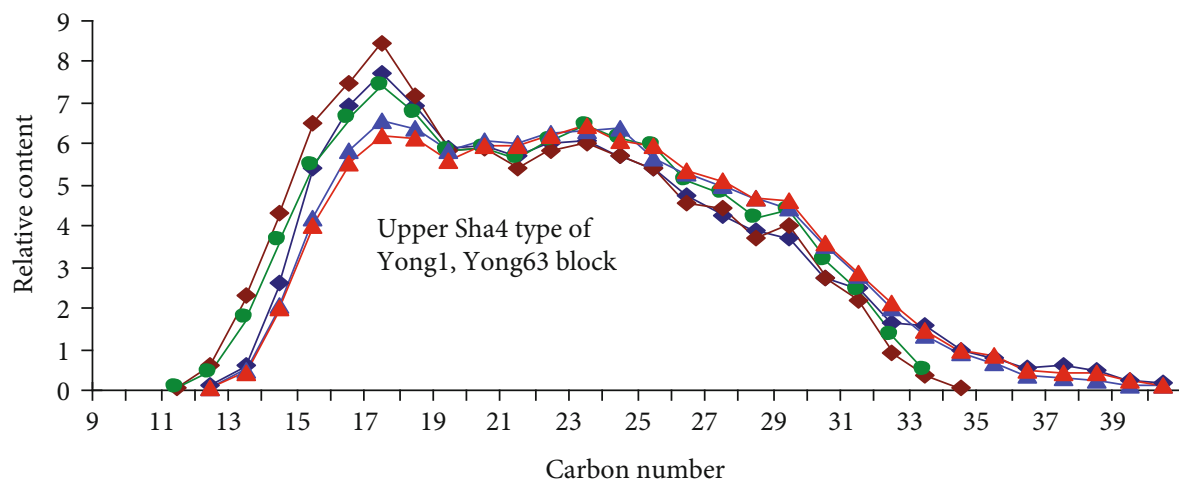

— Feng 1123431.8 Es4s source

- Feng 1123425.58 Es4s source

(f)

FIGURE 2: Comparison diagram of carbon number distributions in some crude oil and hydrocarbon source rocks in the study area of nalkanes. 


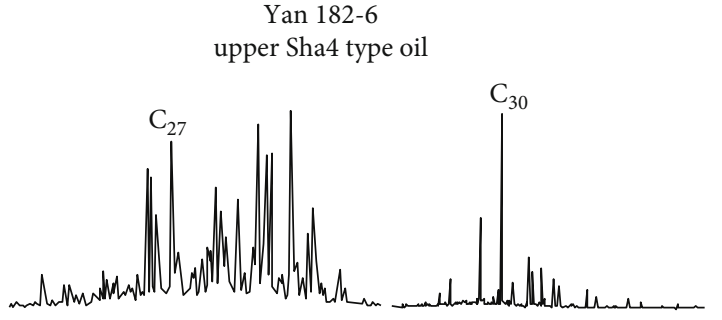

(a)

Feng 112

lower Sha3 type oil

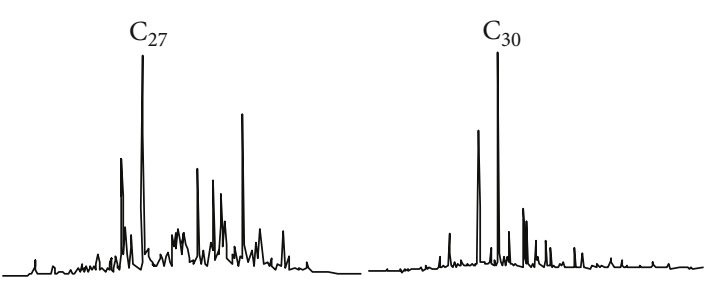

(c)

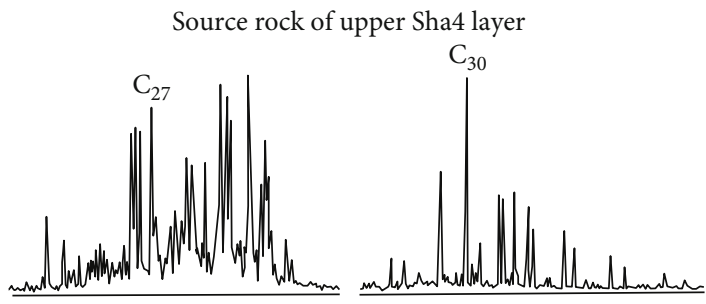

(e)
Yong 2

lower Sha3 and upper Sha4 type mixed oil

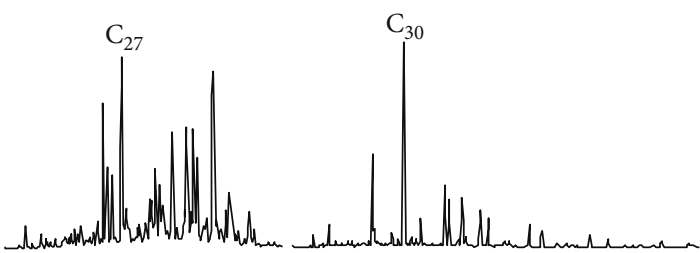

(b)

Yong 63

middle Sha3 and upper Sha4 type mixed oil

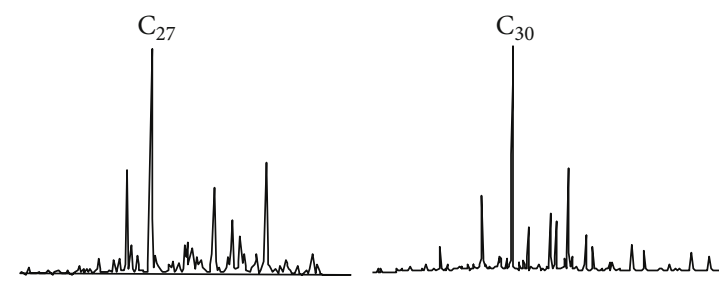

(d)

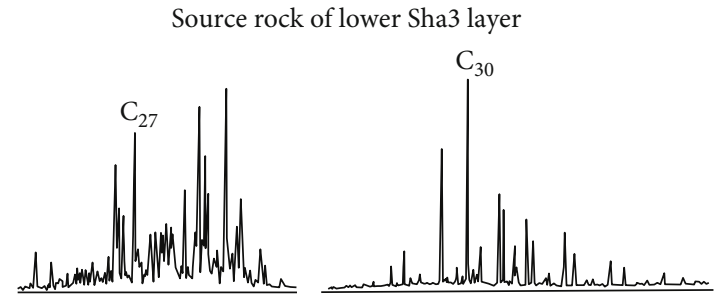

(f)

Source rock of middle Sha3 layer

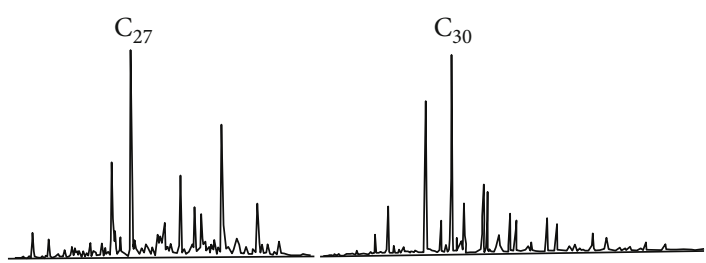

(g)

FIgURE 3: Sterane and terpane fingerprint comparison diagram of the source rocks and crude oil in the study area. (a-d) Are diagrams for crude oil and (e-g) are diagrams for source rock.

\section{Oil-Source Correlation}

In this section, we will investigate the oil-source correlation with the HCA method combined with standard procedures. The traditional oil-source correlation involves various methods, such as the fingerprinting method, parameter comparison method, scatter diagram method, carbon isotope distribution curve method, and other conventional methods $[20,21]$. Since a single method often has limitations and multiple solutions, HCA will be applied to verify further the oilsource relationship in this paper based on the conventional methods.

4.1. Fingerprinting Comparison of Carbon Number Distribution in $n$-Alkanes. The composition and distribution characteristics of $n$-alkanes are affected by multiple factors such as parent material types and organic matter evolution degree, which can be used to identify oil-source relations. The fingerprint contains 25 crude oil samples and 13 source rock samples, including the shape of the n-alkane distribution curve, odd number carbon advantages, and the degree of curve smoothness. Results indicate that the crude oil produced in the Yanjia oil and gas filed, Yong2, Yong3, Yong12, and Yong63 Blocks of Yonganzhen has the features of the upper Sha4 type, while the crude oil produced in Yong66 Block has the characteristics of the combined type of middle Sha3 and lower Sha3; the crude oil produced in Minfeng Sag has the attributes of the lower Sha3 type (Figure 2).

4.2. Sterane and Terpane Fingerprint Comparison. Steranes and terpane are two kinds of essential biomarker compounds, recording shreds of evidence of evolution from the 


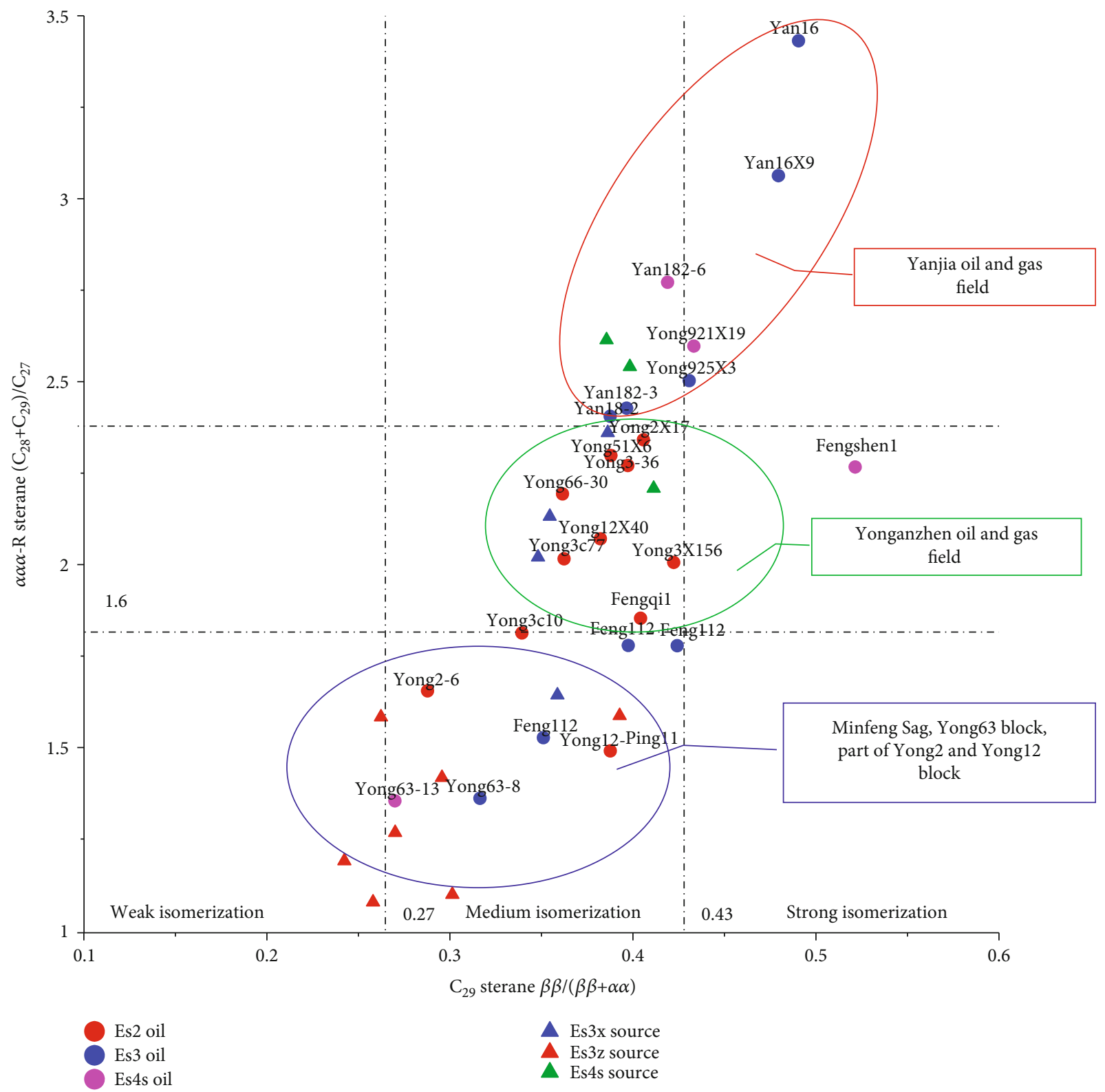

Figure 4: Correlation map between $\alpha \alpha \alpha$ R sterane $\mathrm{C}_{28}+\mathrm{C}_{29} / \mathrm{C}_{27}$ and $\mathrm{C}_{29}$ sterane $\beta \beta /(\beta \beta+\alpha \alpha)$.

biological organic matter to sedimentary organic matter, which can reflect the depositional environment of source rocks and organic matter input [22]. Although the crude oil is generated in the same set of source rock beds, after secondary migration and accumulation, their chemical compositions will change significantly, since a series of geochemical changes would occur due to the changes of geologicalgeochemical conditions, such as the biodegradation and hydrolysis of crude oil in the reservoir, thermal alteration, and fluid-rock interaction and fractionation during the process of oil and gas migration [23]. However, part of the sterane and terpane biomarkers in the crude oil will represent a relatively stable distribution because biodegradation of a light-medium degree, migration effect, and maturity have no apparent impact on them [24].
According to the characteristics of sterane and terpane fingerprints, the $\mathrm{C}_{27}-\mathrm{C}_{28}-\mathrm{C}_{29}$ sterane of source rock and crude oil in the study area distributed as a "V" shape, among which the source rocks of upper Sha4 and lower Sha3 submember have a relatively high content of $\mathrm{C}_{29}$ sterane and high gammacerane index. In contrast, the source rocks of middle Sha3 submember have a relatively high content of $\mathrm{C}_{27}$ sterane and low gammacerane index (Figure 3). Correlation results showed that the crude oil of the Yanjia oil and gas field is the upper Sha4 type; the crude oil of Minfeng Sag is the lower Sha3 type; the crude oil of the Yonganzhen oil field is mixed with various types, which is a combined type of upper Sha4 and lower Sha3 in Yong2, Yong3, Yong12, and Yong66 fault blocks; the crude oil of Yong63 Block is the middle Sha3 type, but its gammacerane content is high in 


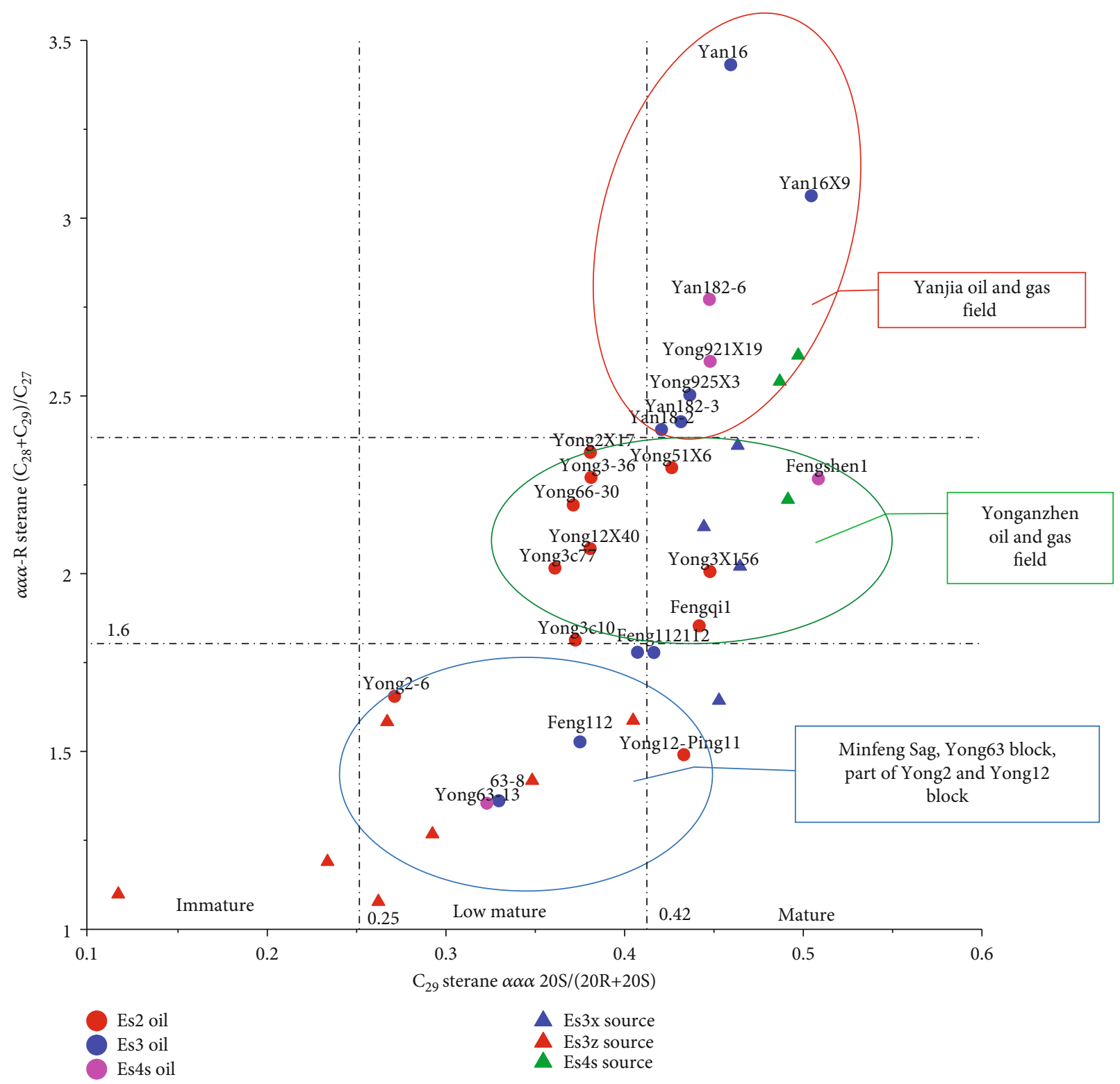

FIGURE 5: Correlation map between $\alpha \alpha \alpha \mathrm{R}$ sterane $\left(\mathrm{C}_{28}+\mathrm{C}_{29}\right) / \mathrm{C}_{27}$ and $\mathrm{C}_{29}$ sterane $\alpha \alpha \alpha 20 \mathrm{~S} /(20 \mathrm{R}+20 \mathrm{~S})$.

terpane. Therefore, it also showed the characteristics of the upper Sha4 type (Figure 4), which needed to be further confirmed combining with maturity indicators.

4.3. Scatter Diagram Method. The parameters used for the scatter diagram methodology this time are parent source and maturity, among which the parent source parameter is the $\mathrm{C}_{29}$ sterane isomerization parameter (includes two types: epimerism and ring isomerism), and the parent source parameter is $\left(\mathrm{C}_{28}+\mathrm{C}_{29}\right) / \mathrm{C}_{27}$ of normal sterane $\alpha \alpha \alpha \mathrm{R}$ biological configuration.

The scatter plot (Figures 5 and 4 ) reveals that three types of crude oil and source rocks with a different parent material and maturity exist in the study area, distributed in three point groups, which indicates the affinities of oil sources intuitively: the first is the sample points of the crude oil of the Yanjia oil and gas field as well as the source rock of lower Sha4 sub- member; the second is the sample points of the source rocks from the lower Sha3 submember and part upper Sha4 submember as well as the crude oil from Yong3 Block (upthrown wall), Yong66 Block, Yong3 Block (7-9 sand groups), Yong 51 Block, and part of Yong 12 Block of the Yonganzhen oil field; the third is the sample points of the crude oil from Yong63 Block, part of Yong2 Block and Yong12 Block, Minfeng Sag, and the source rock of middle Sha3 submember.

4.4. Clustering Method. To avoid multiple solutions, cluster analysis is further adopted with mathematical statistics for the 24 crude oil samples and 14 source rock samples of the study area using 17 geochemical parameters. The clustering method is the correlation coefficient group-averaging method, whose parameters are the gammacerane index, Ts/ $(\mathrm{Ts}+\mathrm{Tm})$, gammacerane content, $\mathrm{C}_{29}$ sterane $\alpha \alpha \alpha 20 \mathrm{~S} /(20 \mathrm{R}$ $+20 \mathrm{~S}), \mathrm{C}_{29}$ sterane $\beta \beta /(\beta \beta+\alpha \alpha), \mathrm{C}_{27}$ sterane $\alpha \beta \beta \mathrm{S} / \alpha \alpha \alpha \mathrm{R}$, 


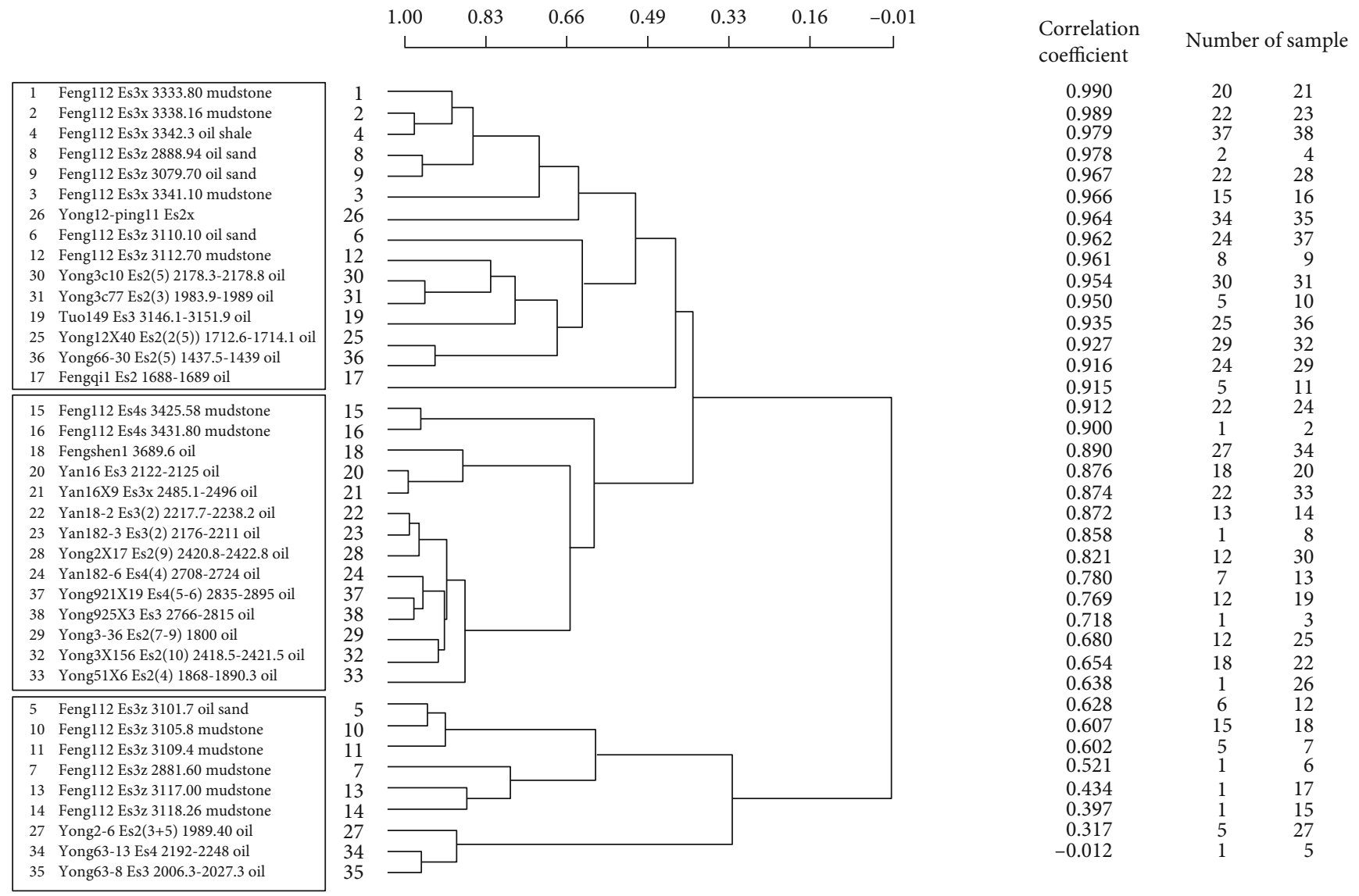

FIGURE 6: Clustering hierarchical diagram by correlation coefficient group averaging method.

$\mathrm{C}_{27}$ steranes $\alpha \alpha \alpha \mathrm{R}, \mathrm{C}_{28}$ steranes $\alpha \alpha \alpha \mathrm{R}, \alpha \alpha \alpha \mathrm{RC} 27+\mathrm{C}_{28}+\mathrm{C}_{29}$ sterane, $\alpha \alpha \alpha \mathrm{RC}_{27} /\left(\mathrm{C}_{27}+\mathrm{C}_{28}+\mathrm{C}_{29}\right)$ steranes, $\alpha \alpha \alpha \mathrm{RC}_{29} /\left(\mathrm{C}_{27}\right.$ $+\mathrm{C}_{28}+\mathrm{C}_{29}$ ) steranes, OEP, CPI, $\sum \mathrm{C}_{21}{ }^{-} / \sum \mathrm{C}_{22}{ }^{+}$, pristane/phytane, and $\mathrm{C}_{17} / \sum \mathrm{C}_{7}{ }^{+}$.

The clustering hierarchical diagram (Figure 6) indicates that the samples of source rocks and crude oil could be divided into three groups: the first group is the crude oil of middle Sha3 submember in Minfeng Sag, the crude oil of Sha2 Member no. 3 and no. 5 sand groups in Yong3 Block, the crude oil of Yong66 Block, the crude oil of Yong12 Block, and the source rocks of lower Sha3 submember and part of middle Sha3 submember, among which the crude oil of middle Sha3 submember and the source rocks of lower Sha3 submember developed in the sag are well correlated with each other whose correlation coefficient reached up to 0.858 , while the correlation coefficient between the crude oil of Sha2 member no. 3 and no.5 sand groups in Yong3 Block, the crude oil of Yong66 Block, the crude oil of Yong12 Block, and the source rocks of middle Sha3 submember is 0.68 . The population correlation coefficient reaches 0.521 .

The second group is the source rock of upper Sha 4 member and the crude oil of the Yanjia oil and gas field and the crude oil of Yong3 Block and Yong 51 Block, among which the correlation coefficient between the crude oil of the Yanjia oil and gas field and the crude oil of Yong3 Block and Yong 51 Block reaches 0.989 , while the population correlation coefficient reaches 0.521 .
The third group is the source rock of middle Sha3 submember and the crude oil of middle Sha3 submember in Minfeng Sag and the crude oil of Yong2 and Yong63 Blocks, among which the crude oil in the sag and the source rocks of middle Sha3 submember are highly correlated with each other, whose maximum correlation coefficient is 0.95 . In contrast, the crude oil of Yong63 Block and Yong2 Block is poorly associated with each other, whose correlation coefficient is less than 0.317 .

Combined with the comparison results of the three methods above, the maturity of the oil-source, and provenance, the oil-source relationship was confirmed: the crude oil of Sha 2 member (no.7 10 sand groups) of Yong3 Block, Sha2 member (no.4 sand group) of Yong51 Block, and the Yan Jia oil and gas field is the upper Sha4 type; the crude oil of the middle Sha3 type and lower Sha3 type was confirmed as the self-generation and self-preservation type that is developed in Minfeng Sag. Besides, the crude oil of the lower Sha3 type is developed in middle Sha3 submember; the crude oil of Sha 2 member (no. 3 and no. 5 sand groups) of Yong3 Block, Yong66 Block, Yong12 Block, and Yong51 Block is the combined type of upper Sha4 and lower Sha3; the crude oil of Yong2 Block (no. 3 and no. 5 sand groups) and Yong63 Block is the middle Sha3 type. The results of oil source correlation on the plane show that only the crude oil of upper Sha4 type is developed in the Yanjia oil and gas field; the crude oil of various types is developed in the 


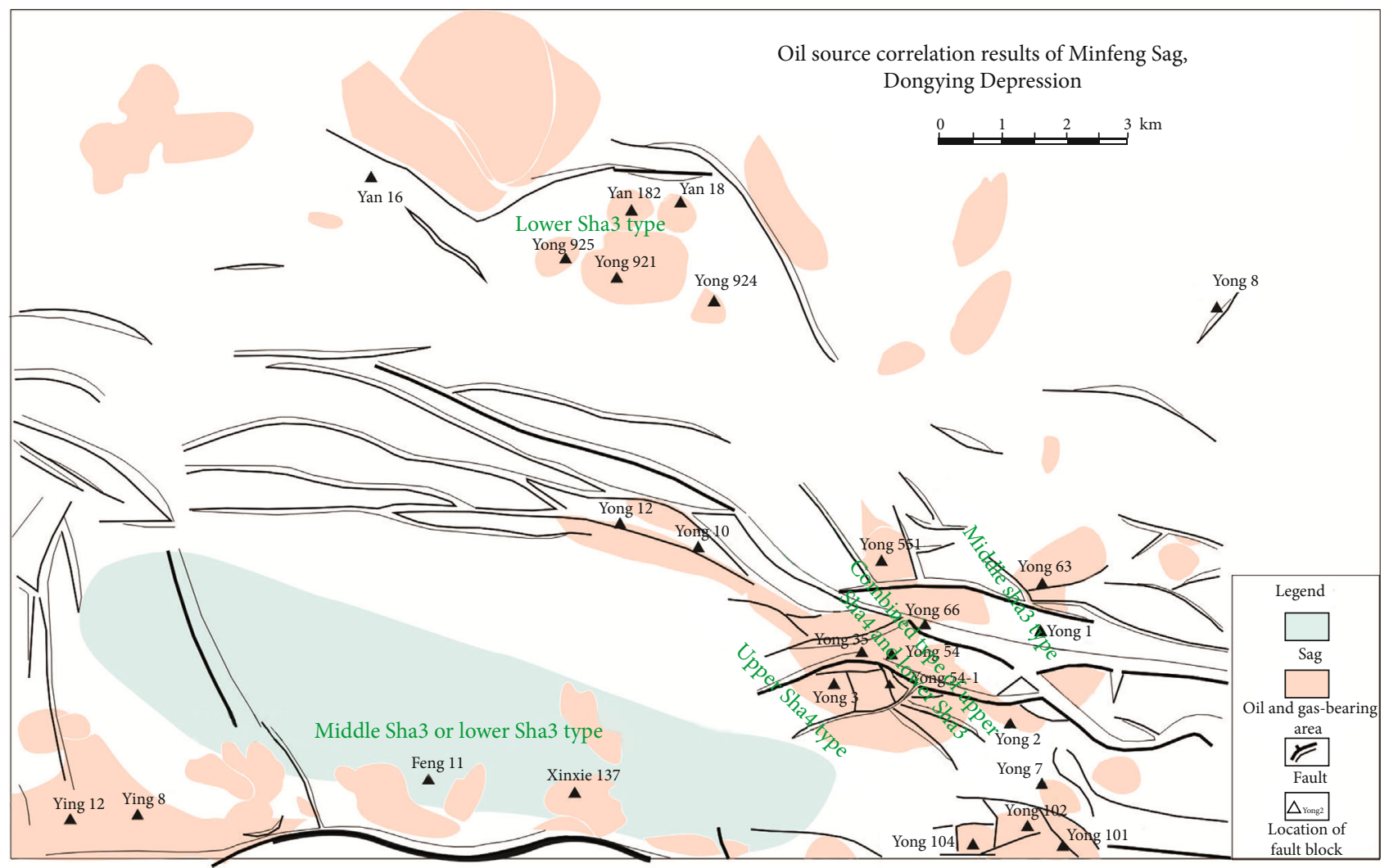

Figure 7: Oil source correlation results and hydrocarbon migration direction of the Minfeng Sag, Dongying Depression.

Yonganzhen oil and gas field, which represents a regular variation from the sag to the Qingtuozi uplift; the crude oil is the upper Sha4 type in the area near the sag, combined type of upper Sha4 and lower Sha3 eastward, and middle Sha3 type far away (Figure 7). It is considered that the traps of the fault blocks in Yonganzhen were formed in the same phase, while the crude oil generated in the early phase charged and accumulated in the fault block of the near source. Along with the increasing of the buried depth of source rock, the overlying source rocks gradually entered into the hydrocarbon generation phase, when crude oil started to charge into the fault blocks farther away.

\section{Conclusions}

(1) There are four types of crude oil with different biomarkers developed in Minfeng area: type A mainly distributes in Sha2 member of Yong3 Block, Sha2 member of Yong51 Block in the Yong Anzhen oil field and Yan Jia oil and gas field. Type B distributes in Sha2 member of Yong3 Block, Yong66 Block, Yong12 Block, and Yong51 Block of Yong Anzhen gas filed. Type $C$ distributes in middle Sha3 submember of Minfeng Sag and Yong2 Block, and Yong63 Block of the Yong Anzhen oil and gas field. Type D distributes in middle Sha3 submember and lower Sha3 submember of Minfeng Sags
(2) Results shed light on the oil-source correlation: the crude oil of Sha2 member of Yong3 Block, Sha2 member of Yong51 Block, and Yan Jia oil and gas field is the upper Sha4 type; the crude oil of the middle Sha 3 type and lower Sha3 type is confirmed as self-generation and self-preservation that is developed in Minfeng Sag. In addition, the crude oil of the lower Sha3 type is developed in middle Sha3 submember; the crude oil of Sha2 member of Yong3 Block, Yong66 Block, Yong12 Block, and Yong51 Block is the combined type of upper Sha4 and lower Sha3; the crude oil of Yong2 Block and Yong63 Block is the middle Sha3 type

(3) The migration and accumulation process is revealed. The crude oil mainly migrated along favorable sand bodies and unconformity surfaces in the lateral direction and then charged and accumulated in the glutenite of Sha3 and Sha4 members since the area from sag to the Yan Jia oil and gas field lacks oil source faults. From Minfeng Sag to Yonganzhen Oilfield and Qing Tuozi uplift, the crude oil represented various types with regular variation, which showed the upper Sha4 type in the fault block of the near source

(4) The traps of the fault block in Yonganzhen were formed in the same phase; the crude oil generated in the early phase charged and accumulated in the fault block of the near source, along with the 
increasing of the buried depth of source rocks and the overlying source rocks gradually entering into the hydrocarbon generation phase, when the crude oil started to charge into the fault blocks farther away

\section{Data Availability}

All data used can be found in our manuscript.

\section{Conflicts of Interest}

The authors declare that they have no conflicts of interest.

\section{References}

[1] J. A. Curiale, "Oil-source rock correlations - Limitations and recommendations," Organic Geochemistry, vol. 39, no. 8, pp. 1150-1161, 2008.

[2] P. K. Mukhopadhyay, J. A. Wade, and M. A. Kruge, "Organic facies and maturation of Jurassic/Cretaceous rocks, and possible oil- source rock correlation based on pyrolysis of asphaltenes, Scotian Basin, Canada," Organic Geochemistry, vol. 22, no. 1, pp. 85-104, 1995.

[3] W. Zhao, C. Jia, L. Jiang et al., "Fluid charging and hydrocarbon accumulation in the sweet spot, Ordos Basin, China," Journal of Petroleum Science and Engineering, vol. 200, p. 108391, 2021.

[4] L. Liu, Z. Zhang, C. Li et al., "Hydrate growth in quartzitic sands and implication of pore fractal characteristics to hydraulic, mechanical, and electrical properties of hydrate-bearing sediments," Journal of Natural Gas Science and Engineering, vol. 75, p. 103109, 2020.

[5] G. Wang, X. Qin, J. Zhou, F. Han, and J. Cai, "Simulation of coal microstructure characteristics under temperaturepressure coupling based on micro-computer tomography," Journal of Natural Gas Science and Engineering, vol. 91, p. 103906, 2021.

[6] C. Wang and G. Shi, "Redox condition and organic carbon accumulation mechanism in the Cryogenian Nanhua Basin, South China: insights from iron chemistry and sulfur, carbon, oxygen isotopes of the Datangpo Formation," Advances in Geo-Energy Research, vol. 3, no. 1, pp. 67-75, 2019.

[7] Z. S. Mashhadi and A. R. Rabbani, "Organic geochemistry of crude oils and Cretaceous source rocks in the Iranian sector of the Persian Gulf: An oil-oil and oil-source rock correlation study," International Journal of Coal Geology, vol. 146, pp. 118-144, 2015.

[8] Z. Chen, T. G. Wang, M. Li, F. Yang, and B. Cheng, "Biomarker geochemistry of crude oils and Lower Paleozoic source rocks in the Tarim Basin, Western China: an oil-source rock correlation study," Marine and Petroleum Geology, vol. 96, pp. 94-112, 2018.

[9] W. Zhao, C. Jia, T. Zhang et al., "Effects of nanopore geometry on confined water flow: a view of lattice Boltzmann simulation," Chemical Engineering Science, vol. 230, article 116183, 2021.

[10] P. F. Greenwood, L. Mohammed, K. Grice, M. McCulloch, and L. Schwark, "The application of compound-specific sulfur isotopes to the oil-source rock correlation of Kurdistan petroleum,” Organic Geochemistry, vol. 117, pp. 22-30, 2018.

[11] L. Zhang, G. Bai, X. Zhao et al., "Oil-source correlation in the slope of the Qikou Depression in the Bohai Bay Basin with dis- criminant analysis," Marine and Petroleum Geology, vol. 109, pp. 641-657, 2019.

[12] W. Zhao, T. Zhang, C. Jia, X. Li, K. Wu, and M. He, "Numerical simulation on natural gas migration and accumulation in sweet spots of tight reservoir," Journal of Natural Gas Science and Engineering, vol. 81, p. 103454, 2020.

[13] H. Huang, S. Zhang, and J. Su, "Palaeozoic oil-source correlation in the Tarim Basin, NW China: a review," Organic Geochemistry, vol. 94, pp. 32-46, 2016.

[14] H. Yang, W. Zhang, K. Wu, S. Li, and Y. Qin, "Uranium enrichment in lacustrine oil source rocks of the Chang 7 member of the Yanchang Formation, Erdos Basin, China," Journal of Asian Earth Sciences, vol. 39, no. 4, pp. 285-293, 2010.

[15] S. Fu, Z. Liu, Y. M. Zhang et al., "Source rocks geochemistry and oil-source correlation in the Aershan and first member of Tengge'er formations of the Wulan-Hua Sag in south of Erlian Basin, Northeastern China," Journal of Petroleum Science and Engineering, vol. 182, p. 106334, 2019.

[16] K. E. Peters, L. S. Ramos, J. E. Zumberge, Z. C. Valin, C. R. Scotese, and D. L. Gautier, "Circum-Arctic petroleum systems identified using decision-tree chemometrics," AAPG Blletin, vol. 91, no. 6, pp. 877-913, 2007.

[17] D. A. Wood and A. Choubineh, "Reliable predictions of oil formation volume factor based on transparent and auditable machine learning approaches," Advances in Geo-Energy Research, vol. 3, no. 3, pp. 225-241, 2019.

[18] I. M. Mohialdeen, M. H. Hakimi, and F. M. Al-Beyati, "Biomarker characteristics of certain crude oils and the oil-source rock correlation for the Kurdistan oilfields, Northern Iraq," Arabian Journal of Geosciences, vol. 8, no. 1, pp. 507-523, 2015.

[19] J. Li, K. Yan, H. Ren, and Z. Sun, "Detailed quantitative description of fluvial reservoirs: a case study of L6-3 layer of sandgroup 6 in the second member of Shahejie Formation, Shengtuo Oilfield, China," Advances in Geo-Energy Research, vol. 4, no. 1, pp. 43-53, 2020.

[20] P. A. Mello, J. S. Pereira, M. F. Mesko, J. S. Barin, and E. M. Flores, "Sample preparation methods for subsequent determination of metals and non- metals in crude oil-a review," Analytica Chimica Acta, vol. 746, pp. 15-36, 2012.

[21] Z. Wang, C. Yang, Z. Yang, C. E. Brown, B. P. Hollebone, and S. A. Stout, Petroleum Biomarker Fingerprinting for Oil Spill Characterization and Source Identification, In standard handbook oil spill environmental forensics, Academic press, 2016.

[22] F. Wang, L. Jiao, J. Zhao, and J. Cai, "A more generalized model for relative permeability prediction in unsaturated fractal porous media," Journal of Natural Gas Science and Engineering, vol. 67, pp. 82-92, 2019.

[23] J. A. Miles, "Secondary migration routes in the Brent sandstones of the Viking Graben and East Shetland Basin: evidence from oil residues and subsurface pressure data," AAPG Bulletin, vol. 74, no. 11, pp. 1718-1735, 1990.

[24] Z. Wang, M. Fingas, C. Yang, and J. H. Christensen, Crude Oil and Refined Product Fingerprinting: Principles, In environmental forensics, Academic press, 1964. 